\title{
(2) OPEN ACCESS \\ Topiramate-induced severe electrolyte abnormalities and hypernatremia leading to central pontine myelinolysis
}

\author{
Luba Muaddi, ${ }^{1,2}$ Omar Osman, ${ }^{1,2}$ Barbara Clark (1) 1,2
}

'Department of Medicine, Allegheny Health Network, Pittsburgh, Pennsylvania, USA ${ }^{2}$ Division of Nephrology and Hypertension, Medicine Institute, Allegheny Health Network, Pittsburgh, PA, USA

Correspondence to Dr Barbara Clark;

barbara.clark@ahn.org and Dr Luba Muaddi;

luba.muaddi@ahn.org

Accepted 15 October 2021

Check for updates

(c) BMJ Publishing Group Limited 2021. Re-use permitted under CC BY-NC. No commercial re-use. See rights and permissions. Published by BMJ.

To cite: Muaddi $L$ Osman O, Clark B. BMJ Case Rep 2021;14:e245870. doi:10.1136/bcr-2021245870

\section{SUMMARY}

Central pontine myelinolysis (CPM) develops due to acute hypernatremia from a normal baseline serum sodium in the setting of electrolyte abnormalities induced by topiramate use. Topiramate is a commonly used medication with several indications including migraines, myoclonic jerks and seizures. It has been reported to cause renal tubular acidosis and severe electrolyte abnormalities, which in turn predispose patients to neuropathology via renal concentration defects and osmotic shifts. Our patient is a 55-year-old woman with a history of multiple sclerosis and myoclonus on topiramate for several years who presented with weakness and was found to be profoundly hypokalemic. She went on to develop changes in mental status, motor deficits and evidence of CPM on MRI during her hospitalisation. Surprisingly, the patient never had hyponatremia; however, she had an acute rise in serum sodium from a normal baseline after fluid resuscitation with normal saline for hypotension during her admission.

\section{BACKGROUND}

Central pontine myelinolysis (CPM) is a rare neuropathology typically associated with rapid correction of hyponatremia. ${ }^{1-3}$ The pons is especially sensitive to osmotic changes and neurological symptoms can occur within 2-3 days. Symptoms can progress within days to include paralysis, 'locked in syndrome' and even coma and death. Thus, it is of utmost importance to prevent significant morbidity and mortality in patients who are predisposed to this condition, especially when disability can be permanent. Interestingly, there has been some controversy regarding other causes and risk factors for CPM which are not widely considered in the medical community. CPM in setting of hypokalemia, hypoglycaemic, malnutrition, hypophosphatemia and alcoholism have been increasingly recognised but seldom reported in absence of hyponatremia. Theoretically, rapid alteration of serum osmolality, as in acute hypernatremia, can overwhelm brain adaptive mechanisms and induce osmotic demyelination syndrome (ODS) regardless of the specific measurement of sodium. In 2015, a case of ODS presenting with hypernatremia was published by Han et al. ${ }^{2}$ Overall, 50 cases have been reported in the literature, 20 case reports and 1 case series of 30 patients. ${ }^{1-3}$ It is possible that the true incidence of CPM in setting of all the abovementioned predisposing factors is actually higher than previously believed.

\section{CASE PRESENTATION}

A 55-year-old woman with a history of multiple sclerosis (MS), gastric bypass, bipolar disorder and myoclonic jerks treated with topiramate presented to an outside hospital with complaints of generalised weakness. She was found to be markedly hypokalemic at $<1.5 \mathrm{mEq} / \mathrm{L}$. The patient had a history of MS flares with similar presentations, last of which was 1 year prior. However, recent follow-up MRI had not shown any new MS-related demyelinated brain lesions. The patient did not have any vomiting or diarrhoea to explain hypokalemia and had reported that she was recently told to decrease topiramate dose due to side effects, rendering topiramate the likely culprit for her severe hypokalemia despite being on potassium supplementation. In addition to metabolic work up for her weakness, hypokalemic periodic paralysis and MS flare were also on the differential for this presentation.

The patient's potassium was aggressively repleted at the outside hospital both orally and intravenously. She had also received $3 \mathrm{~L}$ of intravenous normal saline for hypotension. In review of transfer records, her sodium on day of admission was 137 $\mathrm{mEq} / \mathrm{L}$, but rose to $164 \mathrm{mEq} / \mathrm{L}$ on day 3 of admission, a change of $27 \mathrm{mEq} / \mathrm{L}$ in 72 hours. She was also making around $2.5-3 \mathrm{~L}$ of urine per day during this time, thus raising concern for diabetes insipidus (DI) due to a remote history of lithium use for bipolar disorder. The patient never had issues with hypernatremia or polyuria in the past. Her measured urine osmolality was $400 \mathrm{mOsm} / \mathrm{kg}$, see table 1 for details.

The patient then developed acute onset encephalopathy and left hemiparesis on day 3 . The unilateral upper and lower extremity weakness necessitated ruling out stroke as cause of symptoms and then she was transferred to our hospital for neurological evaluation and higher level of care due to concern for exacerbation of MS versus neurologic vascular event. Neurology did not feel that her presentation was consistent with MS flare or a vascular event. She had an unremarkable lumbar puncture and cerebral imaging.

Nephrology was consulted due to refractory hypokalemia. Review of outside hospital records revealed admission sodium of $137 \mathrm{mEq} / \mathrm{L}$ and normal anion gap metabolic acidosis. She had normal renal function, a urine potassium-to-creatine ratio of $100 \mathrm{mmol} / \mathrm{g}$ and a transtubular potassium gradient of 16 indicating renal potassium wasting. Urine output after resuscitation with intravenous 
Table 1 Laboratory values, intake/output measurements and interventions during hospital course

\begin{tabular}{|c|c|c|c|c|c|c|c|c|c|c|c|}
\hline & Day 0 & Day 1 & Day 2 & Day 3 & Day 4 & Day 5 & Day 6 & Day 7 & Day 8 & Day 9 & Day 10 \\
\hline Sodium (mEq/L) & 137 & 148 & 157 & 164 & 163 & 153 & 152 & 146 & 138 & 145 & 143 \\
\hline Potassium (mEq/L) & $<1.5$ & 2.2 & 2.5 & 2.4 & 3.6 & 2.8 & 3.3 & 3.5 & 3.9 & 3.7 & 2.8 \\
\hline Bicarbonate (mEq/L) & 11 & 13 & 12 & 11 & 12 & 12 & 12 & 13 & 12 & 15 & 19 \\
\hline $\begin{array}{l}\text { Urine osmolality } \\
(\mathrm{m} 0 \mathrm{sm} / \mathrm{kg})\end{array}$ & & & & 401 & 409 & & 431 & & & & 326 \\
\hline Urine sodium (mmol/L) & & & & 34 & & & & & & & 99 \\
\hline Urine creatine (mg/dL) & & & & 53 & & & 48 & & & & 29 \\
\hline $\begin{array}{l}\text { Urine potassium } \\
\text { (mmol/L) }\end{array}$ & & & & 53 & & & & & & & 32 \\
\hline $\begin{array}{l}\text { Intake/output ( } 24 \text { hours } \\
\text { net) (L) }\end{array}$ & $\begin{array}{l}1.7 / 1.47 \\
(+0.23)\end{array}$ & $\begin{array}{l}1.2 / 2.3 \\
(-1.1)\end{array}$ & $\begin{array}{l}1.2 / 2.0 \\
(-0.8)\end{array}$ & $\begin{array}{l}1.6 / 2.7 \\
(-1.1)\end{array}$ & $\begin{array}{l}2.6 / 1.4 \\
(+1.2)\end{array}$ & $\begin{array}{l}1.1 / 1.6 \\
(-0.5)\end{array}$ & $\begin{array}{l}3.5 / 1.2 \\
(+2.3)\end{array}$ & $\begin{array}{l}3.5 / 1.6 \\
(+1.9)\end{array}$ & $\begin{array}{l}3.2 / 3.0 \\
(+0.2)\end{array}$ & $\begin{array}{l}2.0 / 1.77 \\
(+0.23)\end{array}$ & $\begin{array}{l}0.34 / 2.5 \\
(-2.16)\end{array}$ \\
\hline Desmopressin given & & & & & $1 \mathrm{mg}$ & $1 \mathrm{mg}$ & & & & & \\
\hline Events & $\begin{array}{l}\text { Resuscitation with } \\
0.9 \% \text { saline }\end{array}$ & & & $\begin{array}{l}\text { Switch to } \\
\text { Dextrose } \\
5 \% \text { Water }\end{array}$ & & & & & $\begin{array}{l}\text { Switch to } 75 \mathrm{mEq} \\
\text { bicarbonate }\end{array}$ & & \\
\hline
\end{tabular}

normal saline was $>3 \mathrm{~L} /$ day. Her presentation was consistent with renal tubular acidosis (RTA) induced by topiramate. It was concluded that hypernatremia developed due to hypokalemiainduced renal concentrating defect that leads to polyuria rather than lithium-induced DI. The patient was also noted to be hypophosphatemic and folate deficient in the setting of prior gastric bypass predisposing her to ODS. It was highly suspected that the altered mental status was due to ODS rather than MS or stroke given that her acute hypernatremia of $164 \mathrm{mEq} / \mathrm{L}$ was slowly corrected over several days rather than rapidly. Repeat MRI of the brain was pursued and showed a pontine lesion consistent with demyelination (figure 1).

Thereafter, aggressive free water supplementation was implemented to quickly decrease her sodium down to normal range. Her mental status gradually improved after that. She also had resolution of her left arm weakness and was discharged to a short-term physical rehabilitation programme.

\section{INVESTIGATIONS}

For encephalopathy work up, CT scan and angiogram of the head were obtained as part of stroke evaluation and were negative for acute intracranial abnormalities. Initial MRI on day 3 of admission showed multifocal areas of abnormal T2 prolongation in periventricular and subcortical white matter and upper cervical cord, consistent with the history of MS. No active demyelinating lesions were noted. Electroencephalogram (EEG) on day 5 suggested a moderate-to-severe generalised encephalopathy, with significant right-sided slowing greater than left,

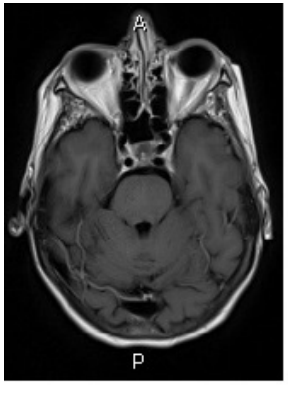

A

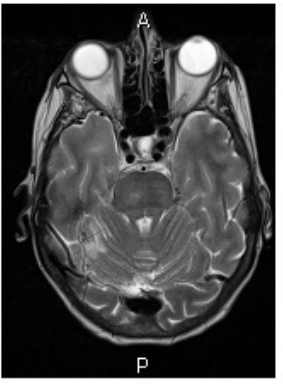

B

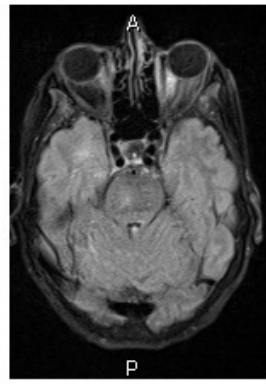

C
Figure 1 Hypointense lesion on T1-weighted image (A) and corresponding hyperintense lesion on T2-weighted image (B) located in the right pons. Flair (C). and right-sided focal lesion should be ruled out, no epileptiform features were seen. EEG the next day redemonstrated the moderate generalised encephalopathic process; however, the asymmetric slowing noted on the prior EEG was not reflected, again no lateralised or epileptiform features were noted. As mentioned previously, lumbar puncture and the Mayo Clinic encephalopathy-autoimmune evaluation panel were negative. Repeat MRI of the head on day 5 now noted a hypointense lesion on T1-weighted image and corresponding hyperintense lesion on T2-weighted image was identified in the right pons consistent with CPM.

In terms of her hypokalemia work up, clinical history and absence of diarrhoea excluded gastrointestinal losses of potassium. Refractoriness to potassium supplementation suggested renal loss. Renal potassium wasting was confirmed by measuring 24 hours potassium excretion ( $125 \mathrm{mmol} / 24$ hours), calculating urine anion gap of +29 , potassium-to-creatine ratio of $100 \mathrm{mmol} / \mathrm{g}$ and transtubular potassium gradient of 16 all in the setting of normal anion gap metabolic acidosis and preserved renal function leading to the diagnosis of proximal RTA. Collection of 24 hours urine potassium is often impractical, our first result was borderline elevated at $125 \mathrm{mmol} / 24$ hours. In the presence of profound hypokalemia, normal renal response would be to conserve potassium and decrease excretion to less than $25 \mathrm{mEq}$ per day. Excretion of over $30 \mathrm{mEq}$ per day is consistent with renal potassium wasting. A spot urine potassium-tocreatine ratio is an acceptable estimate and a result greater than $13 \mathrm{mEq} / \mathrm{g}$ creatine $(1.5 \mathrm{mEq} / \mathrm{mmol})$ points to inappropriate renal potassium loss. The spot urine potassium by itself has limitations in polyuria and can sometimes be misleading. For an accurate estimate, the urine sodium has to be greater than $30 \mathrm{mEq} / \mathrm{L}$ and urine osmolality greater than plasma osmolality suggesting that the patient is not polyuric, hence resulting in the use of potassium-to-creatine ratio to eliminate effect of urine volume. A study by Lin et al in 2004 showed that urine potassium-tocreatine ratio was a reliable tool to distinguish between hypokalemic periodic paralysis and other causes. ${ }^{4}$ It was noted that potassium-to-creatine ratio was significantly lower in patients with periodic paralysis compared with RTA for example. ${ }^{4}$ In addition, patients with periodic paralysis had normal acid-base balance compared with patients without periodic paralysis who often had metabolic alkalosis or metabolic acidosis. Paralysis patients require smaller amount of potassium supplementation as hypokalemia is caused by redistribution of potassium and runs 
the risk of developing hyperkalemia with excess supplementation. Our patient was non-diabetic and had a normal anion gap metabolic acidosis with renal potassium wasting, narrowing her diagnosis to proximal RTA triggered by topiramate with its carbonic anhydrase inhibitor effect. Additional work up included Sjogren syndrome A (SSA) and Sjogren syndrome B (SSB) antibodies to assess for other processes such as Sjogren's and were negative. The development of hypernatremia was attributed at least in part to severe hypokalemia-induced renal concentrating defect but cannot rule out previously undiagnosed underlying chronic lithium injury although this is less likely and lithium had not been used by the patient in years.

\section{DIFFERENTIAL DIAGNOSIS}

Encephalopathy was thought to be multifactorial due to MS pseudoflair in setting of electrolyte derangements with high suspicion of ODS. The clinical picture associated with the changes in MRI could not only represent ODS but can also be seen with subclinical seizures and autoimmune encephalitis. Given that Mayo Clinic encephalopathy-autoimmune evaluation panel was negative, lumbar puncture was unremarkable; lack of history of seizures with an unremarkable EEG, relatively quick recovery of symptoms compared with stroke or MS flare, makes ODS the more likely explanation for this case. This case is important because if the conventional thinking regarding CPM is not broadened or challenged, cases such as this one, out of the context of overcorrection of hyponatremia, will be missed in our daily practice. Reporting this case aims to encourage thinking outside the box and to broaden our horizons as medical specialists.

\section{TREATMENT}

The patient had already received high-dose methylprednisone as part of empiric treatment for MS flare prior to her transfer from the outside hospital, which has been noted to have protective effect on ODS in experimental animal model..$^{5}$ However, the corner stone of treatment was to discontinue topiramate use and replete potassium deficit aggressively to correct the underlying pathology leading to the renal concentration defect and free water loss. Simultaneously, we diligently replenished the patient's free water deficit to correct her sodium levels quickly back to normal range and ameliorate the effect of osmotic change on the pons. The metabolic acidosis was corrected with oral sodium bicarbonate administration as well until serum bicarbonate level was greater than $24 \mathrm{mmol} / \mathrm{L}$. Other routine supportive care measures, including enhancing nutritional status with protein supplements and multivitamins, were implemented and a physical medicine and rehabilitation referral was made to help reverse the neurologic deficit caused.

\section{OUTCOME AND FOLLOW-UP}

Topiramate was indefinitely discontinued and the patient was given extensive education regarding avoiding use in the future. She spent 2 weeks in the hospital before discharge to short-term rehab where she spent $2 \frac{1}{2}$ additional weeks before returning home. Her sodium on discharge from the hospital was $140 \mathrm{mEq} / \mathrm{L}$, bicarbonate was $21 \mathrm{mmol} / \mathrm{L}$ and potassium was $4.2 \mathrm{mEq} / \mathrm{L}$. She had several levels checked during her rehab stay which were all within reference range. She had a repeat basic metabolic panel 2 months post discharge from rehab, which showed sodium of $139 \mathrm{mEq} / \mathrm{L}$, bicarbonate of $24 \mathrm{mmol} / \mathrm{L}$ and potassium of $3.1 \mathrm{mEq} / \mathrm{L}$. The patient was seen in the neurology office for follow-up 1 month post discharge and was becoming stronger and feeling gradually better. She was ambulating with a walker despite slight residual weakness in her left leg. Her topiramate was not restarted and her myoclonic jerks have not reoccurred. It is unclear if she was restarted on potassium supplementation, but hypokalemia is not unexpected as the renal tubular dysfunction can outlast the treatment.

\section{DISCUSSION}

The hypernatremia in this case was due to iatrogenic sodium load during resuscitation in addition to free water loss in a polyuric patient with renal concentration defect induced by topiramate. Topiramate is an antiepileptic medication that inhibits carbonic anhydrase in the proximal convoluted tubule. It leads to lower plasma bicarbonate levels by impairing its reabsorption. It also impairs excretion of acid by the distal renal tubule, causing mixed renal acidosis. This manifests as a hyperchloremic normal anion gap acidosis and alkaline urine. ${ }^{6}$ RTA can be acute or chronic and can cause severe illness, including electrolyte derangements and even demyelinating brain lesions as seen in this patient with risk factors for ODS including hypophosphatemia, hypoglycaemic and hypokalemia.

Hypokalemia has been shown in animal and human studies to cause nephropathy by several mechanisms including renal vasoconstriction, medullary ischaemia and impaired renal angiogenesis as well as tubular brush border damage. ${ }^{7}$ This leads to functional effects on the kidneys including vasopressin-resistant urinary concentration defect though aquaporin 2 channel defects in the collecting duct. $\mathrm{Na}-\mathrm{K}-$ $\mathrm{Cl}$ cotransporters and Renal Outer-Medullary Potassium (ROMK) channels also decrease in the thick ascending loop of Henle leading to decreased sodium reabsorption. Upregulation of angiotensin II, angiotensin I receptor and sodium hydrogen exchanger 3 channels in the proximal tubule also leads to sodium retention.

Clinical features of urinary concentration defect include low urine specific gravity, bland sediment and polyuria, all of which were present in our patient. ${ }^{7}$ While the urine osmolality was not severely dilute (in the $326-400 \mathrm{uOsm} / \mathrm{kg}$ range), it was more dilute than expected in response to the simultaneous plasma osmolality (maximum plasma osmolality was $342 \mathrm{mOsm} / \mathrm{kg}$ ). The onset of urinary concentration defects has been reported within 24 hours in animal studies. Potassium supplementation has also been shown to ameliorate the autophagic degradation of aquaporin 2 channels induced by potassium deprivation as demonstrated by Khositseth et al in $2015 .^{8}$

Although the patient did not have hyponatremia, her sodium increased from $137 \mathrm{mEq} / \mathrm{L}$ to $164 \mathrm{mEq} / \mathrm{L}$ in less than 72 hours. This rapid shift in osmolality may cause myelinolysis in humans. Our patient had a typical radiographic evidence of CPM on MRI with a hyperintense lesion in the pons on T2, the location of the brain most susceptible to osmotic change. Changes have also been seen in extrapontine sites in other cases, these are associated with better recovery. Given the symptoms of unilateral paresis and encephalopathy corresponding to the time of serum sodium increase, her presentation is more consistent with ODS rather than stroke or MS flare. Fortunately, her symptoms improved with the correction of sodium back to the normal range at the rate of $1 \mathrm{mEq} / \mathrm{L} /$ hour. 
Our patient had also been started on steroids as treatment for possible MS flare. Steroids, especially dexamethasone, have been reported to improve the outcome of hypernatremic demyelination in rats by offering protection against osmotic-induced demyelination through preventing disruption of the blood-brain barrier. It is yet unclear whether this played a role in the reversibility of symptoms and better

\section{Learning points}

- The clinical manifestations of acute hypernatremia, including altered mental status and paresis, are similar to those of hyponatremia that are rapidly corrected.

- It is important to avoid overzealous fluid resuscitation, for example, in this case it would have been prudent to change to $5 \%$ dextrose when serum sodium was $148 \mathrm{mEq} / \mathrm{L}$.

- The osmotic stress rather than the absolute value of sodium, whether high or low, seems to correlate more with severity of symptoms.

- The presence of other electrolyte derangements such as hypokalemia and hypophosphatemia certainly increase the risk for osmotic demyelination syndrome.

- Central pontine myelinolysis (CPM) lesions seem to be more common in hyponatremia, while extrapontine lesions are more common in hypernatremia as reported by Ismail et al. They also mentioned that hypernatremic brain osmotic injury is far more common in children than in adults.

- Our case presents a rare occurrence of CPM in a woman who developed CPM due to acute hypernatremia and who fortunately had a good outcome. prognosis in our patient. A follow-up MRI is needed to evaluate the resolution of the CPM lesion.

Contributors All authors participated in data collection and drafting and editing of the manuscript.

Funding The authors have not declared a specific grant for this research from any funding agency in the public, commercial or not-for-profit sectors.

Competing interests None declared.

Patient consent for publication Consent obtained directly from patient(s).

Provenance and peer review Not commissioned; externally peer reviewed.

Open access This is an open access article distributed in accordance with the Creative Commons Attribution Non Commercial (CC BY-NC 4.0) license, which permits others to distribute, remix, adapt, build upon this work non-commercially, and license their derivative works on different terms, provided the original work is properly cited and the use is non-commercial. See: http://creativecommons.org/ licenses/by-nc/4.0/.

\section{ORCID iD}

Barbara Clark http://orcid.org/0000-0002-6696-1424

\section{REFERENCES}

1 Ismail FY, Szóllics A, Szólics M, et al. Clinical semiology and neuroradiologic correlates of acute hypernatremic osmotic challenge in adults: a literature review. AJNR Am J Neuroradiol 2013;34:2225-32.

2 Han MJ, Kim DH, Kim YH, et al. A case of osmotic demyelination presenting with severe hypernatremia. Electrolyte Blood Press 2015;13:30-6.

3 McComb RD, Pfeiffer RF, Casey JH, et al. Lateral pontine and extrapontine myelinolysis associated with hypernatremia and hyperglycemia. Clin Neuropathol 1989;8:284-8.

4 Lin S-H, Lin Y-F, Chen D-T, et al. Laboratory tests to determine the cause of hypokalemia and paralysis. Arch Intern Med 2004;164:1561-6.

5 Sugimura Y, Murase T, Takefuji S, et al. Protective effect of dexamethasone on osmoticinduced demyelination in rats. Exp Neurol 2005;192:178-83.

6 Mirza N, Marson AG, Pirmohamed M. Effect of topiramate on acid-base balance: extent, mechanism and effects. Br J Clin Pharmacol 2009;68:655-61.

7 Yalamanchili HB, Calp-Inal S, Zhou XJ, et al. Hypokalemic nephropathy. Kidney Int Rep 2018;3:1482-8

8 Khositseth S, Uawithya P, Somparn P, et al. Autophagic degradation of aquaporin-2 is an early event in hypokalemia-induced nephrogenic diabetes insipidus. Sci Rep 2015;5:18311.

https://www.bmj.com/company/products-services/rights-and-licensing/permissions/

BMJ Case Report Fellows may re-use this article for personal use and teaching without any further permission.

Become a Fellow of BMJ Case Reports today and you can:

- Submit as many cases as you like

- Enjoy fast sympathetic peer review and rapid publication of accepted articles

- Access all the published articles

Re-use any of the published material for personal use and teaching without further permission

Customer Service

If you have any further queries about your subscription, please contact our customer services team on +44 (0) 2071111105 or via email at support@bmj.com.

Visit casereports.bmj.com for more articles like this and to become a Fellow 